Research Article

\title{
Coupled Vibration Characteristics Analysis of Hot Rolling Mill with Structural Gap
}

\author{
Guangxu Zhang $\mathbb{D}^{1,2}$ Jiahan Bao $\mathbb{D}^{1,2}$ Wenhao Li, ${ }^{1,2}$ Zhichong Wang, ${ }^{1,2}$ \\ and Xiangshuai Meng ${ }^{1,2}$ \\ ${ }^{1}$ Engineering Research Center of Hydraulic Vibration and Control, Ministry of Education, Anhui University of Technology, \\ Maanshan, Anhui, China \\ ${ }^{2}$ School of Mechanical Engineering, Anhui University of Technology, Maanshan, Anhui, China
}

Correspondence should be addressed to Jiahan Bao; baojiahan@126.com

Received 1 February 2021; Revised 6 June 2021; Accepted 9 June 2021; Published 19 June 2021

Academic Editor: Ömer Cívalek

Copyright (c) 2021 Guangxu Zhang et al. This is an open access article distributed under the Creative Commons Attribution License, which permits unrestricted use, distribution, and reproduction in any medium, provided the original work is properly cited.

\begin{abstract}
It is important to study the vibration of rolling mills to improve the stability of rolling production. A dynamic rolling process model is established by considering the elastic recovery of the exit strip and the influence of multiroll equilibrium, and the accuracy of the model is verified by experimental data. On this basis, based on the distribution of friction force in the deformation zone, the rolling force and rolling torque are nonlinearized. In addition, a rolling mill structure model is established by considering the structure gap and a piecewise nonlinear horizontal-vertical-torsional vibration model of the rolling mill is established by combining the structure model and dynamic rolling process model. Finally, the amplitude-frequency characteristics of the work roll under different external excitation amplitude and the dynamic bifurcation characteristics of the work roll under different gaps are analyzed. The study indicates that, by reducing excitation amplitude and structure gap, the system vibration can be reduced. The research results can provide a theoretical reference for further exploration of the coupling vibration of hot rolling mills.
\end{abstract}

\section{Introduction}

In the rolling process, rolling mill vibration is an inevitable problem, which causes vibration of steel strips and wears the parts of rolling mills [1-3]. Therefore, studying rolling mill vibration and put forward vibration suppression methods are beneficial to improve the service life of rolling mill parts and surface quality of rolled pieces.

The study of rolling mill vibration can be regarded as the study of rolling process and rolling mill structure. Most studies on rolling process focus on the roll gap $[4,5]$. For instance, Li et al. [6], Chen et al. [7], and Heidari et al. [8] established the rolling process model by considering the friction on the roll gap and studied horizontal rolling force, vertical rolling force, and neutral angle. Cao et al. [9] and $\mathrm{Ma}$ et al. [10] calculated the rolling force and torque by using the functional relationship. Son et al. [11] established the rolling force model by using the neural network, and the relationship between rolling parameters and rolling force was studied without the modeling analysis of rolling deformation zone. Most studies on rolling mill structure focus on characteristics of horizontal vibration [12], vertical vibration [13], torsional vibration [14], and coupling vibration of rolling mills [15-17]. Wang et al. [18] established a coupled vibration model of rolling mill by considering the offset of the work roll. Peng et al. [19] established a horizontal-vertical vibration model of rolling mill by considering nonlinear hydraulic pressure, nonlinear friction force, and nonlinear rolling force. Zeng et al. [20, 21] established a horizontal-vertical-torsional vibration model of rolling mill by considering the relationship between dynamic rolling conditions and damping coefficient.

However, with the abovementioned study, elastic recovery of exit strip in the rolling process and the gap between work roll bearing seat and mill stand in the rolling mill structure were ignored. There are still some limitations or problems with existing models and studies. Therefore, a 
more complete coupled vibration model of rolling mill needs to be proposed and analyzed.

In this study, we consider the effects of the elastic recovery of exit strip, the force of backup roll on work roll, and the parameter coupling of horizontal, vertical, and torsional directions and establish a dynamic rolling process model. Then, we consider the gap between work roll bearing seat and mill stand and the dynamic rolling process and establish a dynamic nonlinear coupled vibration model of rolling mill. Finally, the bifurcation and amplitude-frequency characteristics of the coupled vibration system of the rolling mill under different conditions are studied.

\section{Dynamic Rolling Process Model}

2.1. Dynamic Rolling Force. It is an ideal rolling process to keep the rolling parameters unchanged and the rolling mill has no vibration. The variable rolling parameters are the excitation source of rolling mill vibration. When the entrance strip thickness changes, the rolling mill will have coupling vibration and it can characterize the rolling continuity $[22,23]$. Therefore, in this paper, the thickness change of the entry strip is an external excitation.

The vibration geometry model of the roll gap is presented by considering elastic recovery in Figure 1. $p$ is the unit rolling force. $f_{1}, f_{2}$, and $f_{3}$ are the frictions in the deformation zone. $R^{\prime}$ is the flattened work roll radius. $H_{\text {in }}, H_{n}$, and $H_{\text {out }}$ are the strip thicknesses at the entry point, thinnest point, and exit point. $l_{1}$ and $l_{2}$ are the contact arc lengths in the deformation zone and elastic zone. $\alpha, \varphi$, and $\beta$ are the bite angle, neutral angle, and exit angle. $v_{0}$ and $v_{1}$ are the strip speeds at the entry and exit points. $v_{r}$ is the rotational speed of the work roll. $\sigma_{H}$ and $\sigma_{h}$ are the front tension and back tension. $x_{3}$ and $y_{3}$ are the dynamic vibration displacements of work roll in the horizontal direction and vertical direction.

Hitchcock indicated that the flattened work roll radius $R^{\prime}$ can be evaluated as [24]

$$
R^{\prime}=R\left[1+\frac{16\left(1-v_{1}^{2}\right) P}{B_{m} \pi E_{1}\left(H_{\text {in }}-H_{n}\right)}\right],
$$

where $v 1$ is the Poisson's ratio; in this research, $v 1=0.3 . E_{1}$ is the Young's modulus of the work roll; in this research, $E_{1}=2.1 \times 10^{5} . B_{m}$ is the average width of the strip; in this research, $B_{m}=1178 \mathrm{~mm}$. $P$ is the total rolling force.

The contact arc length in the deformation zone can be calculated by

$$
l_{1}=\sqrt{R^{\prime}\left(H_{\mathrm{in}}-H_{n}\right)} .
$$

The contact arc length in the elastic zone is related to the variation of average exit strip thickness:

$$
l_{2}=\sqrt{\frac{R^{\prime}\left(H_{n}-H_{\text {out }}\right)}{2}} .
$$

The strip thickness at the entry point can be calculated by

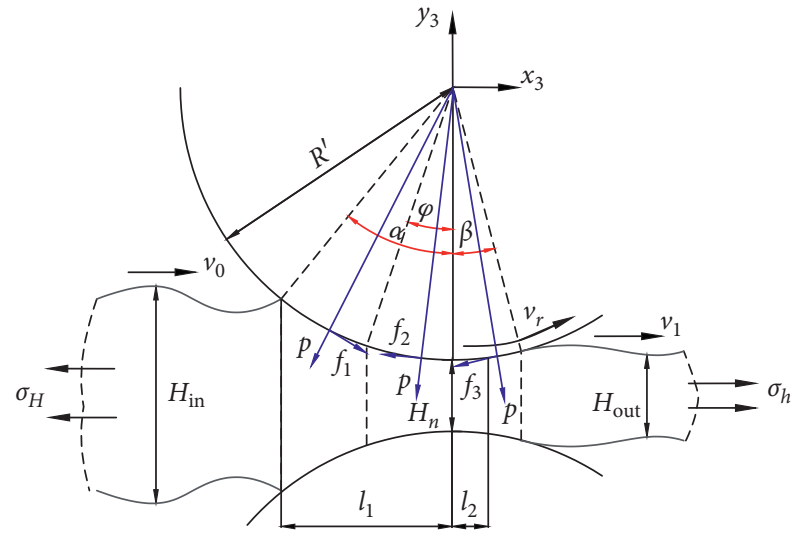

FIGURE 1: Vibration geometry model of the roll gap.

$$
H_{\text {in }}=H+2 \Delta H,
$$

where $\Delta H$ is half of the strip thickness change at the entry point.

The strip thickness at the exit point can be calculated by

$$
H_{\text {out }}=h+2 y_{3} .
$$
by

The strip thickness at the thinnest point can be calculated

$$
\begin{aligned}
H_{n} & =h p^{\prime}+2 y_{3} \\
& =h p+Q_{h p}(h-h p)+2 y_{3},
\end{aligned}
$$

where $Q_{h p}$ is the strip elasticity coefficient; $h p$ is the original roll gap spacing. Because of the rolling reaction force, the strip thickness at the thinnest point will be changed, $h p \longrightarrow h p^{\prime}$. by

The rolling speed at the neutral point can be calculated

$$
v_{r}^{\prime}=v_{r}+\dot{x}_{3} \cos \phi+\dot{y}_{2} \sin \phi+R^{\prime} \dot{\theta}_{2},
$$

where $\dot{\theta}_{2}$ is the angular velocity; $\dot{x}_{3}$ is the vibration velocity in the horizontal direction; $\dot{y}_{3}$ is the vibration velocity in the vertical direction.

The friction coefficient is related to roll roughness, rolling speed, roll wear, and lubrication, so the friction coefficient is calculated by [25]

$$
\mu=\mu_{0}\left[1+\mu_{v} e^{-\left(v / v_{r}\right)}\right] \cdot\left[1+\mu_{r}\left(r-r_{0}\right)\right] \cdot\left[1+\frac{\mu_{L}}{1+\left(L / L_{0}\right)}\right],
$$

where $\mu_{0}$ is the basic friction coefficient; $\mu_{v}$ is the speed influence coefficient of friction; $v$ is the rolling speed; $\mu_{r}$ is the work roll roughness coefficient; $r$ and $r_{0}$ are actual work roll roughness and roughness of unused work roll; $\mu_{L}$ is the friction influence coefficient; $L$ and $L_{0}$ are the actual rolling length and datum rolling length.

Friction is divided into three parts and the vertical force is balanced: 


$$
\begin{aligned}
P_{S y} \approx & P=\int_{0}^{\alpha} p B_{m} R^{\prime} \cos \theta \mathrm{d} \theta+\int_{0}^{\beta} p B_{m} R^{\prime} \cos \theta \mathrm{d} \theta \\
& +\int_{\phi}^{\alpha} \mu p B_{m} R^{\prime} \sin \theta \mathrm{d} \theta \\
& -\int_{0}^{\phi} \mu p B_{m} R^{\prime} \sin \theta \mathrm{d} \theta+\int_{0}^{\beta} \mu p B_{m} R^{\prime} \sin \theta \mathrm{d} \theta .
\end{aligned}
$$

From (9), the neutral angle can be given as

$$
\phi=\sqrt{\frac{\alpha^{2} f_{1}+\beta^{2} f_{3}}{f_{1}+f_{2}}},
$$

where $\alpha$ and $\beta$ can be calculated by

$$
\left\{\begin{array}{l}
\alpha=\frac{l_{1}}{R^{\prime}}, \\
\beta=\frac{l_{2}}{R^{\prime}} .
\end{array}\right.
$$

The rolling force can be calculated by [2]

$$
\begin{aligned}
P & =\int_{0}^{l_{1}}\left(p-\sigma_{m}\right) B_{m} \mathrm{~d} l+\int_{0}^{l_{2}}\left(p-\sigma_{m}\right) B_{m} \mathrm{~d} l \\
& =\left(p-\sigma_{m}\right) B_{m}\left(l_{1}+l_{2}\right),
\end{aligned}
$$

where $\sigma_{m}$ is the average value of tension:

$$
\sigma_{m}=\frac{\sigma_{H} H_{\text {in }}+\sigma_{h} H_{\text {out }}}{2} .
$$

T.-M. Zhi indicated that the unit rolling force $\mathrm{p}$ can be evaluated as follows [26]:

$$
p=1.15 Q_{p} \sigma_{S},
$$

where

$$
\left\{\begin{array}{l}
\sigma_{s}=2.744 \cdot e^{((5.0 / T)-(0.01 / c+0.05))}\left(\frac{\dot{\varepsilon}}{10}\right)^{m \varepsilon} \cdot\left[1.3\left(\frac{\varepsilon}{0.2}\right)^{n}-0.3\left(\frac{\varepsilon}{0.2}\right)\right] \\
m \varepsilon=(0.019 c+0.126) T+(0.075 c+0.05) \\
T=\frac{t+273}{1000} \\
\varepsilon=\ln \frac{H_{\mathrm{in}}}{H_{n}}, \\
\dot{\varepsilon}=\frac{v_{r}^{\prime}}{l_{1}} \ln \frac{H_{\mathrm{in}}}{H_{n}}-\frac{\dot{y}_{3}}{\alpha \sqrt{R^{\prime} H_{n}}} \arctan \left(\alpha \sqrt{\frac{R^{\prime}}{H_{n}}}\right) \\
Q_{p}=0.8+C \sqrt{\left(\frac{R}{H_{\text {in }}}-0.5\right)} \\
C=0.2 \varepsilon+0.12,
\end{array}\right.
$$

where $t$ is the rolling temperature; $c$ is the carbon content (\%) in the strip; in this research, $c=0.0925 \%$.

2.2. Dynamic Rolling Torque. The force of backup roll on work roll is presented in Figure 2. $O_{1}$ is the center of the work roll, and $\mathrm{O}_{2}$ is the center of the backup roll. $a, b$, and $m$ are the arms of force. $F_{D}$ is the force of backup roll on work roll. $e$ is the horizontal distance of the work roll from the backup roll. $R_{D}$ is the backup roll radius. $a$ and $b$ are arms of force. $\gamma_{1}$ is the rolling force-deflection angle. $\gamma_{2}$ is the force-deflection angle of backup roll on work roll. $\gamma_{3}$ is the work roll deflection angle.

The Rolling torque is calculated by [26]

$$
\begin{aligned}
M_{S} & =P a+F_{D} b \\
& =P R \sin \left(\phi \pm \gamma_{1}\right)+F\left(m \cos \gamma_{2}+R_{D} \sin \gamma_{2}\right),
\end{aligned}
$$

where 


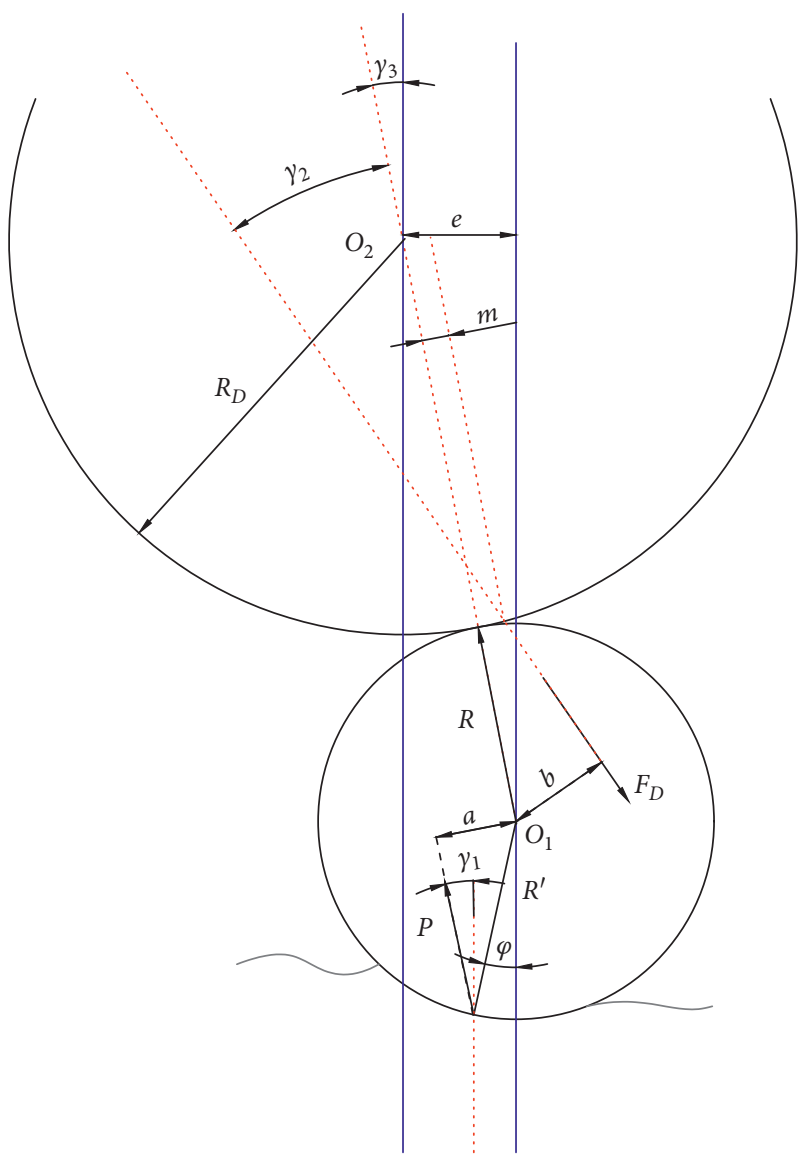

FIGURE 2: Force of backup roll on work roll.

$$
\left\{\begin{array}{l}
F_{D}=\frac{P \cos \gamma_{1}}{\cos \left(\gamma_{2}+\gamma_{3}\right)}, \\
\sin \gamma_{2}=\frac{\mu_{1} R_{D}+m}{R_{D}}, \\
\sin \gamma_{3}=\frac{e}{R_{D}+R}, \\
\sin \gamma_{1}=\frac{\sigma_{H} H_{\text {in }} B_{m}-\sigma_{h} H_{\text {out }} B_{m}}{2 P} .
\end{array}\right.
$$

In this research, $m=0.1 \sim 0.3 \mathrm{~mm} . \mu_{1}$ is the friction coefficient of bearing; in this research, $\mu_{1}=0.004$.

2.3. Data Validation. The rolling conditions in this research are shown in Table 1. The comparison between the actual and calculated parameters is presented in Figure 3.

As shown in Figure 3, the maximum relative error between the actual rolling force and the calculated rolling force with $l_{2}$ is less than $5 \%$. The maximum relative error between the actual rolling torque and the calculated rolling torque with $l_{2}$ is less than $10 \%$. The results show that this model has high accuracy. Without $l_{2}$, the maximum relative error between the actual rolling force and calculated rolling force
TABLE 1: Rolling conditions.

\begin{tabular}{lccccc}
\hline Parameters & 1 stand & 2 stand & 3 stand & 4 stand & 5 stand \\
\hline$H_{\text {in }}(\mathrm{mm})$ & 34.89 & 17.27 & 8.63 & 5.41 & 3.59 \\
$H_{n}(\mathrm{~mm})$ & 15.86 & 8.32 & 5.29 & 3.56 & 2.52 \\
$H_{\text {out }}(\mathrm{mm})$ & 17.27 & 8.63 & 5.41 & 3.59 & 2.53 \\
$v_{r}(\mathrm{~m} / \mathrm{s})$ & 1.05 & 2.50 & 4.05 & 6.15 & 8.79 \\
$\sigma_{H}(\mathrm{MPa})$ & 0 & 9.05 & 9.97 & 12.39 & 14.57 \\
$\sigma_{h}(\mathrm{MPa})$ & 9.05 & 9.97 & 12.39 & 14.57 & 16.55 \\
$t\left({ }^{\circ} \mathrm{C}\right)$ & 985.60 & 967.74 & 951.80 & 931.37 & 916.92 \\
$P(\mathrm{~N})$ & $2 \times 71 \times 10^{7}$ & $2 \times 44 \times 10^{7}$ & $2 \times 39 \times 10^{7}$ & $2 \times 24 \times 10^{7}$ & $1 \times 79 \times 10^{7}$ \\
$M_{S}(\mathrm{kN} \cdot \mathrm{m})$ & 1914.96 & 1170.91 & 650.22 & 437.64 & 258.82 \\
\hline
\end{tabular}

is $15 \%$, and the maximum relative error between the actual rolling torque and calculated rolling torque is $25 \%$. The results show that the elastic recovery of the exit strip has more influence on rolling torque than rolling force.

2.4. Processing of Dynamic Rolling Parameters. The coupled vibration of rolling mills shows that the rolling parameters in horizontal, vertical, and torsional directions are coupled.

The horizontal force can be calculated by

$$
\begin{aligned}
P_{S x}= & \int_{0}^{\alpha} p B_{m} R^{\prime} \sin \theta \mathrm{d} \theta-\int_{0}^{\beta} p R^{\prime} B_{m} \sin \theta \mathrm{d} \theta \\
& -\int_{\phi}^{\alpha} \mu p R^{\prime} B_{m} \cos \theta \mathrm{d} \theta+\int_{0}^{\beta} \mu p R^{\prime} B_{m} \cos \theta \mathrm{d} \theta \\
& +\int_{0}^{\phi} \mu p R^{\prime} B_{m} \cos \theta \mathrm{d} \theta+\frac{\sigma_{H} H_{\mathrm{in}} B_{m}-\sigma_{h} H_{\mathrm{out}} B_{m}}{2} .
\end{aligned}
$$

Based on Taylor expansion, the strip thickness and rolling speed are separated, and the rolling force is nonlinear in the vertical direction.

$$
\left\{\begin{array}{l}
P_{S y}\left(H_{\mathrm{in}}\right)=P_{y}+\Delta P_{y}(\Delta H) \\
=P_{y}+a_{1} \Delta H+a_{2} \Delta H^{2}+a_{3} \Delta H^{3} \\
P_{S y}\left(H_{n}\right)=P_{y}+\Delta P_{y}\left(y_{3}\right) \\
=P_{y}+a_{4} y_{3}+a_{5} y_{3}^{2}+a_{6} y_{3}^{3} \\
P_{S y}\left(v_{r}^{\prime}\right)=P_{y}+\Delta P_{y}\left(\dot{y}_{3}\right) \\
=P_{y}+a_{7} \dot{y}_{3}+a_{8} \dot{y}_{3}^{2}+a_{9} \dot{y}_{3}^{3}
\end{array}\right.
$$

where $a_{1}-a_{6}$ are the stiffness coefficients in the vertical direction; $a_{7}-a_{9}$ are the damping coefficients in the vertical direction.

$\Delta P_{x}$ and $\Delta P_{y}$ are much smaller than $P_{S x}$ and $P_{S y}$ and can be ignored. The deviation angle between the horizontal rolling force and rolling force can be calculated by

$$
\begin{aligned}
\psi & =\frac{P_{S x}}{P} \approx \frac{P_{S x}}{P_{S y}} \\
& =\frac{P_{x}+\Delta P_{x}}{P_{y}+\Delta P_{y}} \approx \frac{P_{x}}{P_{y}} .
\end{aligned}
$$




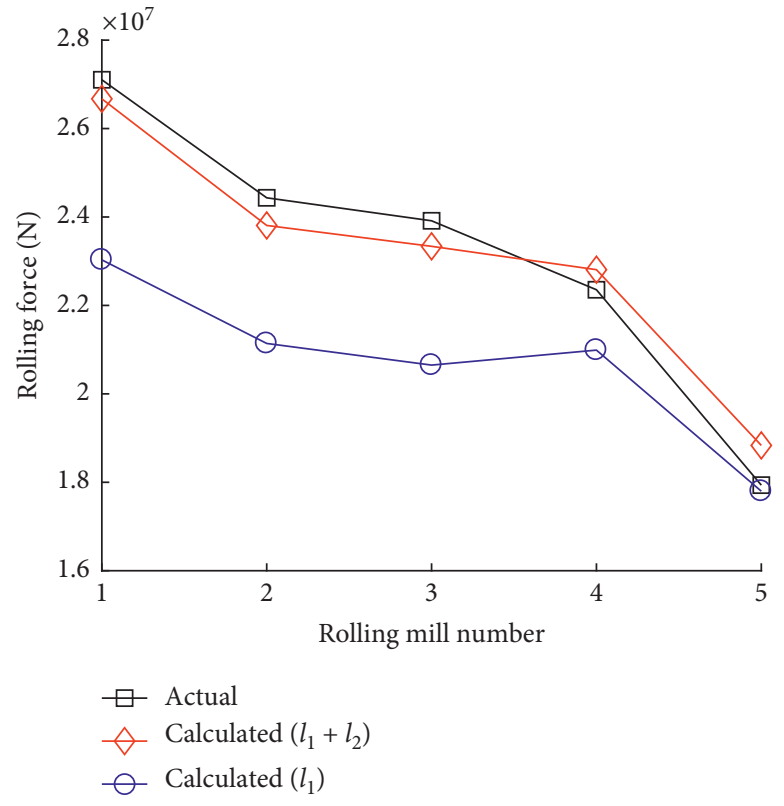

(a)

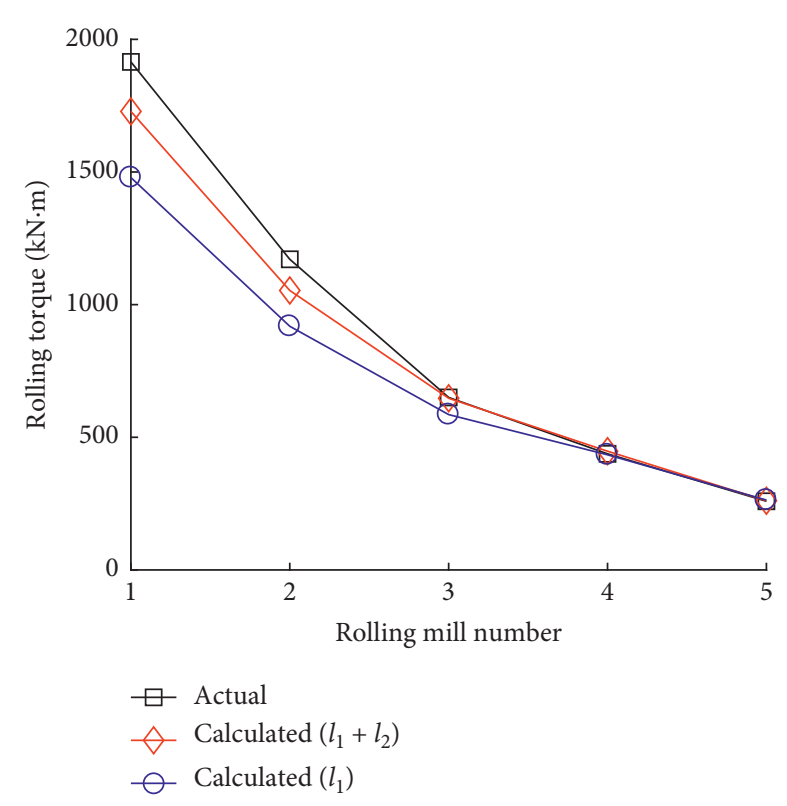

(b)

FIgURE 3: Comparison between the actual parameters and calculated parameters: (a) rolling force; (b) rolling torque.

Based on (21) and Taylor expansion, the nonlinear horizontal rolling force can be expressed as

$$
\left\{\begin{array}{l}
P_{S x}\left(H_{\text {in }}\right)=\left[P_{y}+\Delta P_{y}(\Delta H)\right] \psi+\Delta T(\Delta H) \\
=P_{x}+\Delta P_{x}(\Delta H) \\
=P_{x}+b_{1} \Delta H+b_{2} \Delta H^{2}+b_{3} \Delta H^{3} \\
P_{S x}\left(H_{n}\right)=P_{x}+\Delta P_{y}\left(y_{3}\right) \psi+\Delta T\left(y_{3}\right) \\
=P_{x}+\Delta P_{x}\left(x_{3}\right) \\
=P_{x}+b_{4} x_{3}+b_{5} x_{3}^{2}+b_{6} x_{3}^{3} \\
P_{S x}\left(v_{r}^{\prime}\right)=P_{x}+\Delta P_{y}\left(\dot{y}_{3}\right) \psi \\
=P_{x}+\Delta P_{x}\left(\dot{x}_{3}\right) \\
=P_{x}+b_{7} \dot{x}_{3}+b_{8} \dot{x}_{3}^{2}+b_{9} \dot{x}_{3}^{3},
\end{array}\right.
$$

where $b_{1}-b_{6}$ are the stiffness coefficients in the horizontal direction; $b_{7}-b_{9}$ are the damping coefficients in the horizontal direction.

Based on Taylor expansion, the nonlinear rolling torque can be written as

$$
\left\{\begin{array}{l}
M_{S}\left(H_{n}\right)=M+\Delta M\left(\theta_{2}\right) \\
=M+c_{1} \theta_{2}+c_{2} \theta_{2}^{2}+c_{3} \theta_{2}^{3}, \\
M_{S}\left(v_{r}^{\prime}\right)=M+\Delta M\left(\dot{\theta}_{2}\right) \\
=M+c_{4} \dot{\theta}_{2}+c_{5} \dot{\theta}_{2}^{2}+c_{6} \dot{\theta}_{2}^{3},
\end{array}\right.
$$

where $c_{1}-c_{3}$ are the stiffness coefficients in the torsion direction; $c_{4}-c_{6}$ are the damping coefficients in the torsion direction.
In this study, $P, P_{S y}, P_{S x}$, and $M_{S}$ are variable mechanical parameters. $P_{x}, P_{y}$, and $M$ are the mechanical parameters in the steady state of the vibration system of the hot rolling mill. $\Delta P_{x}, \Delta P_{y}$, and $\Delta M$ are the dynamic values of the mechanical parameters in the unsteady state. Therefore, equations (19), (21), and (22) are dynamic nonlinear equations and the rolling process model has a lot of nonlinear and coupling factors.

\section{Nonlinear Vibration Model}

Figure 4 is the nonlinear horizontal-vertical-torsional coupled vibration model considering the gap between work roll bearing seat and mill stand, friction on the stand, and nonlinearity of backup roll.

As shown in Figure $4, M_{1}, M_{2}$, and $M_{3}$ are the equivalent mass of the upper part of mill stand, backup roll, and work roll. $J_{1}$ and $J_{2}$ are the rotational inertia of electrical machinery and upper rolls system of the rolling mill. $K_{1}, K_{2}, K_{3}$, and $K_{4}$ are the equivalent vertical stiffness. Based on Duffing theory, $K_{2 x}+K_{1 x} \cdot x_{2}^{2}$ is the equivalent horizontal stiffness of backup roll. In this research, $K_{1 x}=\left|b_{6}\right| . K_{3 x}$ is the equivalent horizontal stiffness of the work roll. $K_{1 z}$ and $C_{p y}$ are equivalent torsional stiffness and equivalent vertical damping. $F_{f 2}$ and $F_{f 3}$ are the frictions on the mill stand. $e_{1}$ is the gap between the work roll bearing seat and the mill stand. $x_{i}, y_{i}$, and $\theta_{i}$ are horizontal, vertical, and torsional displacements.

The equivalent horizontal stiffness $K_{23 x}$ is calculated by

$$
K_{23 x}=\frac{P_{S}}{\xi} \sin \theta,
$$




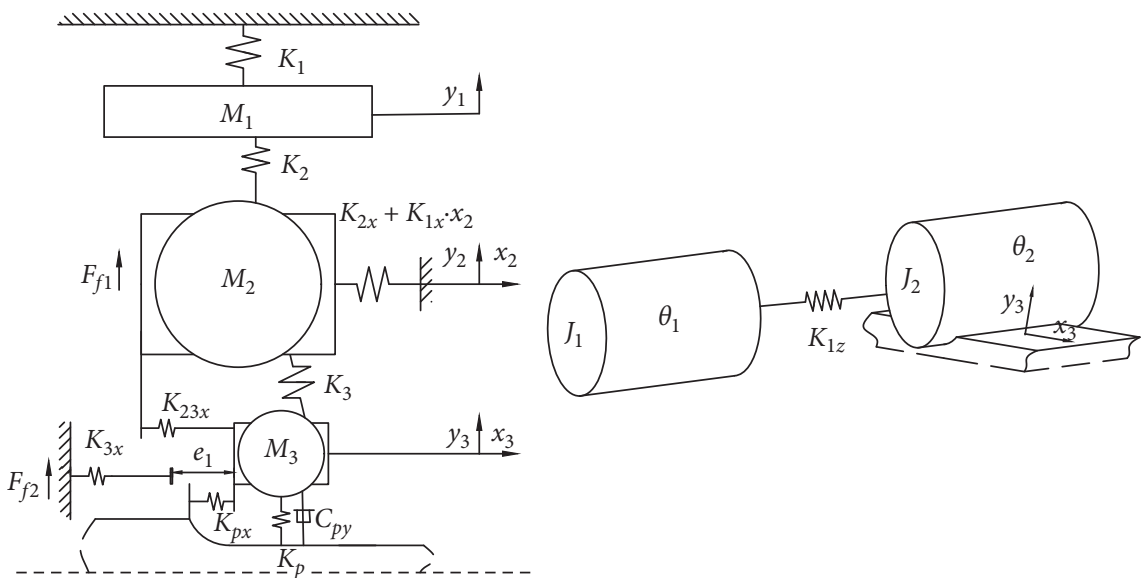

FIgURE 4: Geometry of the vertical-horizontal-torsional vibration model.

where $\xi$ is the roll flattening. Hertz indicated that the roll flattening $\xi$ can be evaluated as

$$
\xi=\frac{p_{m}}{\pi}\left(\frac{1-v_{1}^{2}}{\pi E_{1}}+\frac{1-v_{2}^{2}}{\pi E_{2}}\right) \ln \frac{3.04\left(2 R+2 R_{D}\right)}{p_{m}\left(\left(1-v_{1}^{2} / \pi E_{1}\right)+\left(1-v_{2}^{2} / \pi E_{2}\right)\right)} .
$$

The equivalent vertical damping between the work roll and strip can be calculated by

$$
C_{p y}=\frac{d P_{S}}{d \dot{\varepsilon}}
$$

In this research, torsional vibration is considered to be caused by horizontal vibration.

$$
\Delta M=R\left(b_{4} x_{3}+b_{5} x_{3}^{2}+b_{6} x_{3}^{3}\right) .
$$

According to the Lagrange theory, the horizontal-vertical-torsional coupled vibration equation can be written as

$$
\left\{\begin{array}{l}
M_{2} \ddot{x}_{2}+\left(K_{2 x}+K_{23 x}+K_{1 x} x_{2}^{2}\right) x_{2}-K_{23 x} x_{3}=0, \\
M_{3} \ddot{x}_{3}-K_{23 x} x_{2}+\left(K_{23 x}+K_{p x}\right) x_{3}+f\left(x_{3}\right) \\
+\Delta P_{x}\left(\dot{x}_{3}\right)+\Delta P_{x}\left(x_{3}\right)=\Delta P_{x}(\Delta H), \\
M_{1} \ddot{y}_{1}+\left(K_{1}+K_{2}\right) y_{1}-K_{2} y_{2}=0, \\
M_{2} \ddot{y}_{2}-K_{2} y_{1}+\left(K_{2}+K_{3}\right) y_{2}-K_{3} y_{3}=-\mu_{2} K_{2 x} x_{2}, \\
M_{3} \ddot{y}_{3}-K_{3} y_{2}+\left(K_{3}+K_{p}\right) y_{3}+C_{p y} \dot{y}_{3}+\Delta P_{y}\left(\dot{y}_{3}\right) \\
+\Delta P_{y}\left(y_{3}\right)=\Delta P_{y}(\Delta H), \\
J_{1} \ddot{\theta}_{1}+K_{1 z} \theta_{1}-K_{1 z} \theta_{2}=0, \\
J_{2} \ddot{\theta}_{2}+K_{1 z} \theta_{2}-K_{1 z} \theta_{1}+\Delta M\left(\theta_{2}\right)+\Delta M\left(\dot{\theta}_{2}\right)=\Delta M .
\end{array}\right.
$$

The gap between the work roll bearing seat and mill stand and the friction are expressed by piecewise functions:

$$
\begin{aligned}
f\left(x_{3}\right) & = \begin{cases}K_{3 x} x_{3}, & x_{3} \geq 0, x_{3} \leq-e_{1}, \\
0, & 0>x_{3}>-e_{1},\end{cases} \\
F_{f 3} & = \begin{cases}\mu_{3} K_{3 x} x_{3}, & x_{3} \geq 0, x_{3} \leq-e_{1}, \\
0, & 0>x_{3}>-e_{1} .\end{cases}
\end{aligned}
$$

Table 2 shows the vibration parameters of the 1580 hot rolling mill [27].

\section{Analysis of Vibration Stability}

4.1. Analysis of Amplitude-Frequency Characteristics. In this research, $\Delta H=H_{1} \cos (\omega t)$, where $\omega=2 \pi f$. We use the average method to solve the dynamic response of the system [28]. Equation (29) has periodic solutions:

$$
\begin{aligned}
z_{x, y, \theta} & =N_{i} \cos \left(\omega t+\psi_{i}\right) \\
& =N_{i} \cos \phi_{i},
\end{aligned}
$$

where

$$
\left\{\begin{array}{l}
z_{x, y, \theta}=\left[x_{2}, x_{3}, y_{1}, y_{2}, y_{3}, \theta_{1}, \theta_{2}\right]^{T}, \\
i=[1,2,3,4,5,6,7]^{T}, \\
N_{i}=[A, B, C, D, E, F, G]^{T} .
\end{array}\right.
$$

The phase angle and displacement of (29) change weakly.

$$
\begin{aligned}
\dot{z}_{x, y, \theta} & =-\omega N_{i} \sin \phi_{i} \\
& =-\omega N_{i} \sin \phi_{i}+\dot{N}_{i} \cos \phi_{i}-N_{i} \dot{\psi}_{i} \sin \phi_{i}, \\
\ddot{z}_{x, y, \theta} & =-\omega^{2} N_{i} \cos \phi_{i}+\omega \dot{N}_{i} \sin \phi_{i}-\omega N_{i} \dot{\psi}_{i} \sin \phi_{i} .
\end{aligned}
$$

From (31), the relationship between phase angle and displacement can be given as

$$
\dot{N}_{i} \cos \phi_{i}-N_{i} \dot{\psi}_{i} \sin \phi_{i}=0 \text {. }
$$

Substituting equations (29)-(33) into (27), and the vibration is averaged, we obtain

$$
\left\{\begin{array}{l}
\dot{N}_{i}=-\frac{1}{2 \omega \pi} \int_{0}^{2 \pi} f\left(z_{x, y, \theta}, \dot{z}_{x, y, \theta}\right) \sin \phi_{i} \mathrm{~d} \phi_{i}, \\
\dot{\psi}_{i}=-\frac{1}{2 \omega N_{i} \pi} \int_{0}^{2 \pi} f\left(z_{x, y, \theta}, \dot{z}_{x, y, \theta}\right) \cos \phi_{i} \mathrm{~d} \phi_{i},
\end{array}\right.
$$


TABLE 2: Structural and technological parameters of the 1580 hot rolling mill.

\begin{tabular}{lc}
\hline Parameter & Value \\
\hline$M_{1}(\mathrm{~kg})$ & 94300 \\
$M_{2}(\mathrm{~kg})$ & 50150 \\
$M_{3}(\mathrm{~kg})$ & 28622 \\
$J_{1}\left(\mathrm{~kg} \cdot \mathrm{m}^{2}\right)$ & 10500 \\
$J_{2}\left(\mathrm{~kg} \cdot \mathrm{m}^{2}\right)$ & 1310 \\
$K_{1}(\mathrm{~N} / \mathrm{m})$ & $5.21 \times 10^{10}$ \\
$K_{2}(\mathrm{~N} / \mathrm{m})$ & $2.89 \times 10^{10}$ \\
$K_{3}(\mathrm{~N} / \mathrm{m})$ & $6.84 \times 10^{10}$ \\
$K_{2 x}(\mathrm{~N} / \mathrm{m})$ & $1.82 \times 10^{9}$ \\
$K_{3 x}(\mathrm{~N} / \mathrm{m})$ & $2.5 \times 10^{9}$ \\
$K_{1 z}(\mathrm{~N} / \mathrm{m})$ & $2.5 \times 10^{7}$ \\
$e(\mathrm{~mm})$ & 10 \\
\hline
\end{tabular}

where $f\left(z_{x, y, \theta}, \dot{z}_{x, y, \theta}\right)$ are the functions of horizontal, vertical, and torsional vibration.
We think $\dot{N}_{i}=\dot{\psi}_{i}=0$, and amplitude-frequency characteristics equations of the rolling mill can be obtained.

$$
\left\{\begin{array}{l}
-K_{23 x} B+K_{2 x} A+K_{23 x} A-\omega^{2} M_{2} A+\frac{3}{4} K_{1 x} A^{3}=0 \\
\left(-A K_{23 x}+B K_{23 x}+\frac{B K_{3 x}}{2}+B K_{p x}+b_{4} B+\frac{3}{4} b_{6} B^{3}-\omega^{2} M_{3} B\right)^{2}+\left(b_{7} B \omega+\frac{3}{4} b_{9} \omega^{3} B^{3}\right)^{2}=\left[b_{1} H_{1}+\frac{3}{4} b_{3} H_{1}^{3}\right]^{2} \\
-K_{2} D+K_{1} C+K_{2} C-\omega^{2} M_{1} C=0 \\
-K_{2} C+K_{3} D+K_{2} D-K_{3} E-\omega^{2} M_{2} D+\mu_{2} K_{2 x} A=0 \\
\left(E K_{3}-D K_{3}+a_{4} E+\frac{3}{4} a_{6} E^{3}+K_{p} E-\omega^{2} M_{3} E+\frac{\mu_{3} K_{3 x} B}{2}\right)^{2}+\left(C_{p y} \omega E+a_{7} E \omega+\frac{3}{4} a_{9} \omega^{3} E^{3}\right)^{2}=\left[a_{1} H_{1}+\frac{3}{4} a_{3} H_{1}^{3}\right]^{2} \\
K_{1 z} F-K_{1 z} G-\omega^{2} M_{2} F=0, \\
\left(K_{1 z} G+c_{1} G+\frac{3}{4} c_{3} G^{3}-K_{1 z} F-\omega^{2} M_{2} G\right)^{2}+\left(c_{4} G \omega+\frac{3}{4} c_{6} \omega^{3} G^{3}\right)^{2}=\left[R\left(b_{4} B+\frac{3}{4} b_{6} B^{3}\right)\right]^{2} .
\end{array}\right.
$$

The amplitude-frequency characteristics of the work roll under different thickness variations of the entry strip are shown in Figure 5. In this paper, $H_{1}$ could be considered an external excitation. The amplitudes of horizontal, vertical, and torsional vibrations of the system become bigger with the increase of the amplitude of external excitation. When $H_{1}=0 \mathrm{~mm}$, the rolling mill does not vibrate and this shows that the system is stable without excitation. When $38 \mathrm{~Hz}<f<52 \mathrm{~Hz}$, the resonant amplitudes of the system in three directions have multiple solutions under $H_{1}=2 \mathrm{~mm}$ and this shows that the system is unstable. The resonant zones of the system in three directions are the same under $H_{1}=2 \mathrm{~mm}$ and $70 \mathrm{~Hz}<f<85 \mathrm{~Hz}$, and this shows that the system has two horizontal-vertical-torsional coupling resonance zones under $38 \mathrm{~Hz}<f<85 \mathrm{~Hz}$ and $H_{1}=2 \mathrm{~mm}$. In addition, the system has two separate resonance zones in the torsion direction under $0<f<38 \mathrm{~Hz}$ and $H_{1}=2 \mathrm{~mm}$, and the system has one separate resonance zone in the vertical vibration under $150 \mathrm{~Hz}<f<180 \mathrm{~Hz}$ and $H_{1}=2 \mathrm{~mm}$. This is because the structure of the rolling mill in horizontal, vertical, and torsion directions is different, the system has single direction resonance. Furthermore, the coupling relationships of the rolling mill make the system have multidirectional coupling resonance. The violent resonance can be reduced by reducing the external excitation amplitude of the rolling mill.

4.2. Analysis of Bifurcation Characteristics. Figure 6 shows the dynamic bifurcation diagram of the work roll vibration under different gaps between the work roll bearing seat and 


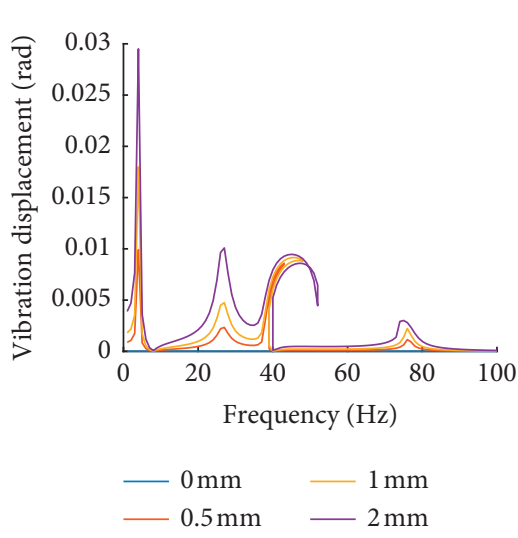

(a)
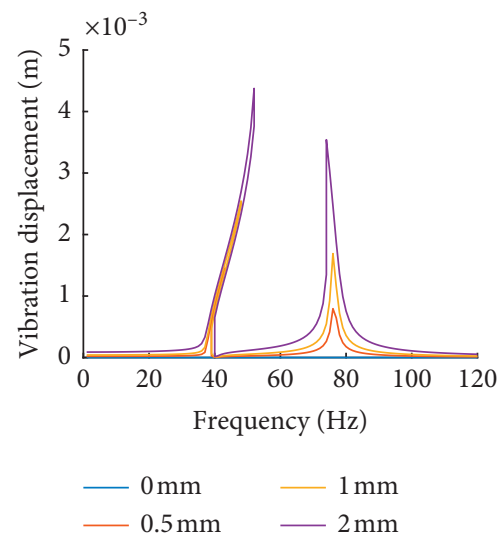

(b)

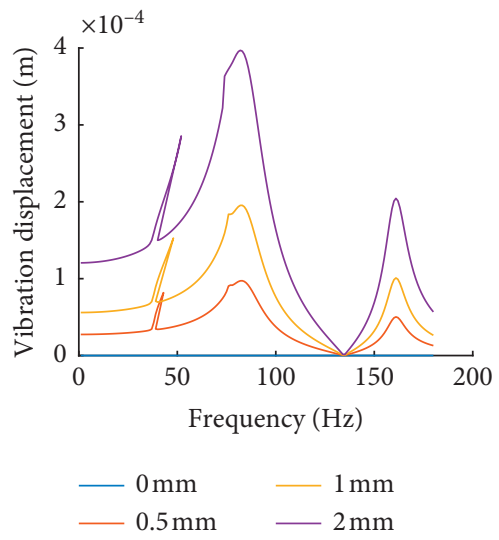

(c)

FiguRE 5: Frequency domain vibration signal of the work roll: (a) vibration acceleration in the torsional direction; (b) vibration acceleration in the vertical direction; (c) vibration acceleration in the horizontal direction.

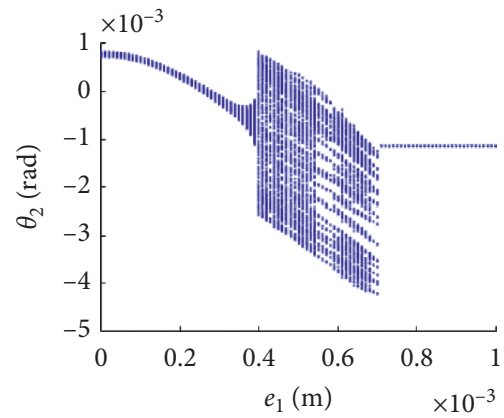

(a)

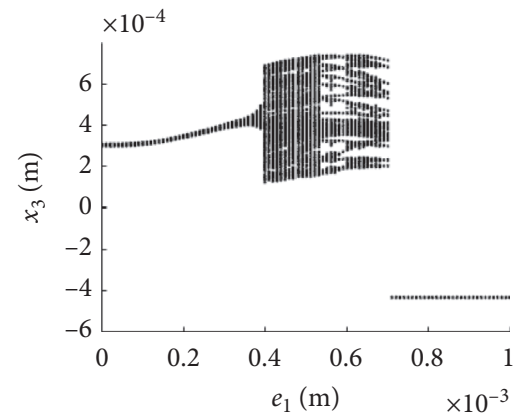

(b)

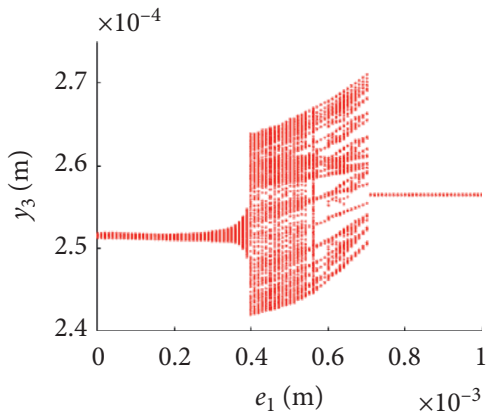

(c)

FIgURE 6: Bifurcation diagram under varying structure gap: (a) torsional direction; (b) vertical direction; (c) horizontal direction.

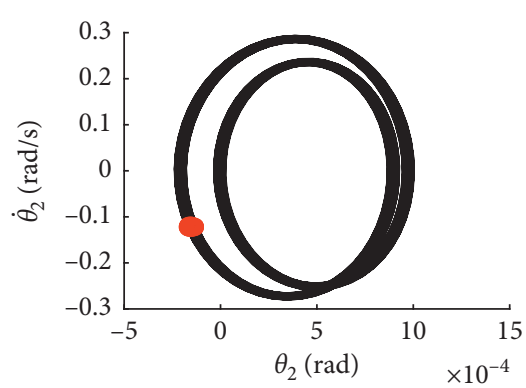

(a)

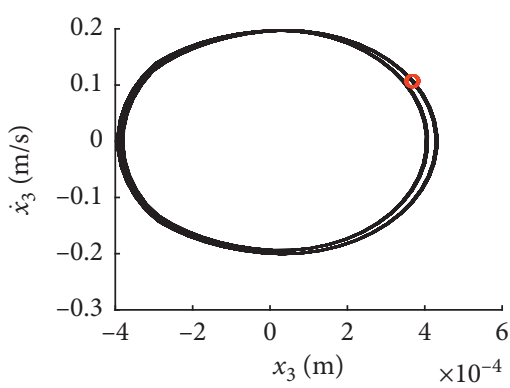

(b)

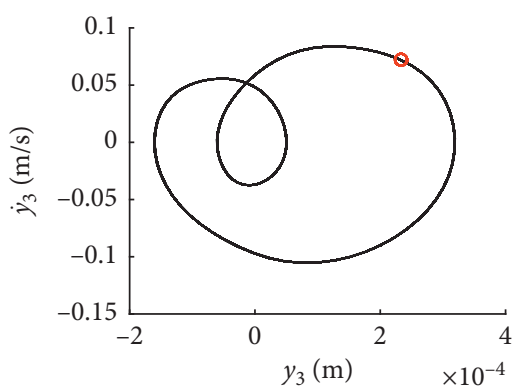

(c)

FIgURE 7: Bifurcation diagram under $0.3 \mathrm{~mm}$ structure gap: (a) torsional direction; (b) vertical direction; (c) horizontal direction.

the mill stand. Figures 7 and 8 show the phase path and Poincare section under different gaps.

As Figures 6(a)-6(c) show, the dynamic bifurcation characteristics of horizontal, vertical, and torsional vibrations are the same, which also reflects the coupling. When $e_{1}<0.4 \mathrm{~mm}$, the system vibration is periodic motion and the corresponding phase path and Poincare section are single, which indicates that the system runs steadily. When $e_{1}>0.4 \mathrm{~mm}$, the system enters chaotic motion and the corresponding phase path and Poincare section are multiple, which indicates that the system runs unstable and affects the quality of strip. As Figure 6(b) shows, when $e_{1}>0.7 \mathrm{~mm}$, the horizontal vibration amplitude of the system is less than the gap. But in fact, the probability of this situation is very small, 


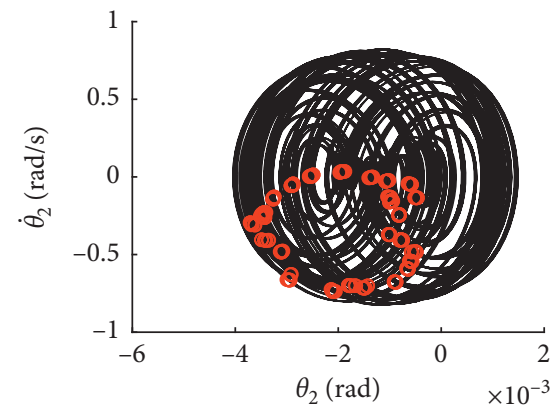

(a)

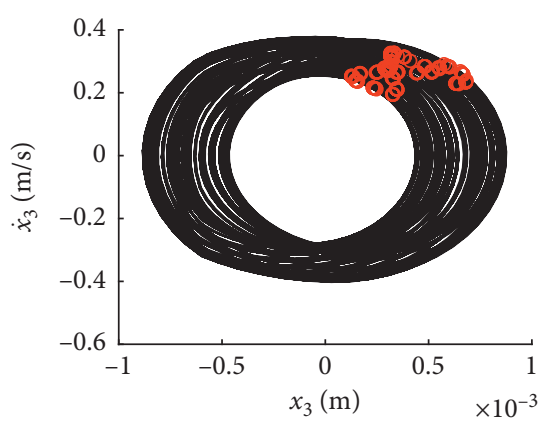

(b)

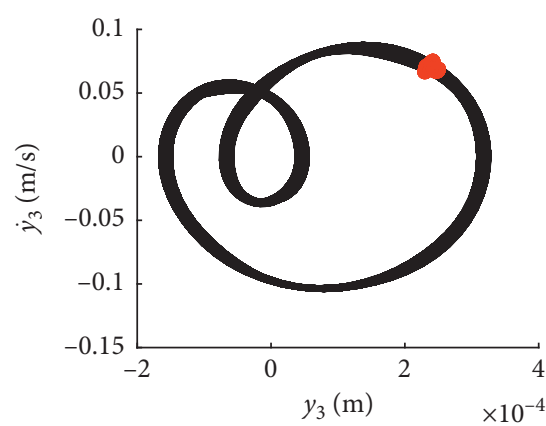

(c)

FIgURE 8: Bifurcation diagram under $0.6 \mathrm{~mm}$ structure gap: (a) torsional direction; (b) vertical direction; (c) horizontal direction.

so we do not do research. Therefore, the unstable resonance can be avoided by reducing the gap between the work roll bearing seat and the mill stand.

\section{Conclusion}

(1) In the dynamic nonlinear rolling process model, elastic recovery, multiroll equilibrium, and parameter coupling were considered. Furthermore, the elastic recovery of the exit strip has more influence on rolling torque than rolling force. In the coupled structure model of the rolling mill, the structure gap, roll offset, and structure coupling were considered. Finally, the piecewise nonlinear horizontal-verticaltorsional coupled vibration model of the rolling mill was established as the entrance strip thickness changes, which reflects the continuity of rolling.

(2) From the study of amplitude-frequency characteristics of the hot rolling mill under varying external excitation amplitude, it was found that, in the system, there exist single direction resonance and multidirectional coupling resonance. In addition, the resonant amplitude of the hot rolling mill can be reduced by reducing the external excitation amplitude.

(3) From the study of the bifurcation characteristics of the coupling vibration of the hot rolling mill under varying structural gaps, it was found that period motion and chaos motion exist in horizontal, vertical, and torsional directions. Further, the coupling vibration of the hot rolling mill can be stable if the gap is maintained below the critical value.

To sum up, we can reduce the amplitude of external excitation and structure gap to suppress the vibration of the rolling mill and ensure the stable operation of the system.

\section{Data Availability}

The structural and conditions data of rolling mill used to support the findings of this study are included within the article.

\section{Conflicts of Interest}

The authors declare that there are no conflicts of interest regarding the publication of this paper.

\section{Acknowledgments}

This work was supported by the Key Program of Natural Science Research of Higher Education in Anhui Province of China (No. KJ2018ZD005).

\section{References}

[1] V. Panjković, R. Gloss, J. Steward, S. Dilks, R. Steward, and G. Fraser, "Causes of chatter in a hot strip mill: observations, qualitative analyses and mathematical modelling," Journal of Materials Processing Technology, vol. 212, no. 4, pp. 954-961, 2012.

[2] Z. Gao, Y. Zang, and L.-Q. Zeng, "Review of modelling and theoretical studies on chatter in the rolling mills," Journal of Mechanical Engineering, vol. 51, no. 16, pp. 87-112, 2015.

[3] L. Hadji and M. Avcar, "Nonlocal free vibration analysis of porous FG nanobeams using hyperbolic shear deformation beam theory," Advances in Nano Research, vol. 10, no. 3, pp. 281-293, 2021.

[4] F.-S. Du, G.-G. Wang, X.-L. Zang, and X.-T. Li, "Friction model for strip rolling," Journal of Iron and Steel Research International, vol. 17, no. 7, pp. 19-23, 2010.

[5] Z. Y. Jiang and A. K. Tieu, "Elastic-plastic finite element method simulation of thin strip with tension in cold rolling," Journal of Materials Processing Technology, vol. 130-131, no. 20, pp. 511-515, 2002.

[6] W.-G. Li, C. Liu, N. Feng, X. Chen, and X.-H. Liu, "Friction estimation and roll force prediction during hot strip rolling," Journal of Iron and Steel Research International, vol. 23, no. 12, pp. 1268-1276, 2016.

[7] S. Chen, W. Li, and X. Liu, "Calculation of rolling pressure distribution and force based on improved karman equation for hot strip mill," International Journal of Mechanical Sciences, vol. 89, no. 12, pp. 256-263, 2014.

[8] A. Heidari, M. R. Forouzan, and M. R. Niroomand, "Development and evaluation of friction models for chatter simulation in cold strip rolling," International Journal of Advanced Manufacturing Technology, vol. 96, no. 2, pp. 2055-2075, 2018.

[9] J.-Z. Cao, D.-W. Zhao, S.-H. Zhang, W. Peng, S.-Z. Chen, and D.-H. Zhang, "Analysis of hot tandem rolling force with logarithmic velocity field and EA yield criterion," Journal of Iron and Steel Research International, vol. 21, no. 3, pp. 295-299, 2014.

[10] G.-S. Ma, Y.-M. Liu, W. Peng et al., "A new model for thermomechanical coupled analysis of hot rolling," Journal of the 
Brazilian Society of Mechanical Sciences and Engineering, vol. 39, no. 2, pp. 1-8, 2015.

[11] J.-S. Son, D.-M. Lee, I.-S. Kim, and S.-G. Choi, "A study on on-line learning neural network for prediction for rolling force in hot-rolling mill," Journal of Materials Processing Technology, vol. 164-165, pp. 1612-1617, 2005.

[12] H. Li, B. Wen, and J. Zhang, "Asymptotic method and numerical analysis for self-excited vibration in rolling mill with clearance," Shock and Vibration, vol. 8, Article ID 262743, 2001.

[13] M. Mosayebi, F. Zarrinkolah, and K. Farmanesh, "Calculation of stiffness parameters and vibration analysis of a cold rolling mill stand," International Journal of Advanced Manufacturing Technology, vol. 91, no. 9, pp. 4359-4369, 2017.

[14] D. Han, P. Shi, and K. Xia, "Nonlinear torsional vibration dynamics behaviors of rolling mill's multi-DOF main drive system under parametric excitation," Journal of Applied Mathematics, vol. 2014, Article ID 202686, 7 pages, 2014.

[15] X.-B. Fan, Y. Zang, and K. Jin, "Rolling process and its influence analysis on hot continuous rolling mill vibration," Applied Physics, vol. 1221008 pages, 2016.

[16] H. Alwan and M. Avcar, "Analytical solution of free vibration of FG beam utilizing different types of beam theories: a comparative study," Computers and Concrete, vol. 26, no. 3, pp. 285-292, 2020.

[17] M. Avcar, "Effects of material non-homogeneity and two parameter elastic foundation on fundamental frequency parameters of timoshenko beams," Acta Physica Polonica A, vol. 130, no. 1, pp. 375-378, 2016.

[18] R. Wang, Y. Peng, Y. Zhang, and J.-L. Sun, "Mechanism research of rolling mill coupled vibration," Journal of $\mathrm{Me}$ chanical Engineering, vol. 49, no. 12, pp. 66-71, 2013.

[19] R.-R. Peng, X.-Z. Zhang, and P.-M. Shi, "Coupled vibration behavior of hot rolling mill rolls under multinonlinear effects," Shock and Vibration, vol. 2020, Article ID 6104028, 14 pages, 2020.

[20] L.-Q. Zeng, Y. Zang, and Z.-Y. Gao, "Multiple-modal-coupling modeling and stability analysis of cold rolling mill vibration," Shock and Vibration, vol. 2016, Article ID 2347386, 26 pages, 2016.

[21] L. Zeng, Y. Zang, Z.-Y. Gao, and X.-C. Liu, "Study on overall coupled modeling of the rolling mill," Journal of Mechanical Engineering, vol. 51, no. 14, pp. 46-53, 2015.

[22] X. Wang and X. Yan, "Dynamic model of the hot strip rolling mill vibration resulting from entry thickness deviation and its dynamic characteristics," Mathematical Problems in Engineering, vol. 2019, Article ID 5868740, 11 pages, 2019.

[23] X. Lu, J. Sun, G. Li, Q. Wang, and D. Zhang, "Dynamic analysis of vibration stability in tandem cold rolling mill," Journal of Materials Processing Technology, vol. 272, pp. 47$57,2019$.

[24] X. Lu, J. Sun, G. Li, Z. Wang, and D. Zhang, "Stability analysis of a nonlinear coupled vibration model in a tandem cold rolling mill," Shock and Vibration, vol. 2019, Article ID 4358631, 14 pages, 2019.

[25] S.-Z. Chen, D.-H. Zhang, J. Sun, J.-S. Wang, and J. Sun, "Online calculation model of rolling force for cold rolling mill based on numerical integration," in Proceedings of the 2012 24th Chinese Control And Decision Conference (CCDC), Taiyuan, China, May 2012.

[26] Y. K. Sun, Model and Control of Cold and Hot Rolling Strip Mill, Metallurgical Industry Press, Beijing, China, 2010.

[27] W. Guo, Vertical-horizontal Vibration Research on Simplified Model of Hot Continuous Rolling Mill during Dynamic Rolling
Process, Anhui University of Technology, Ma'anshan, China, 2019.

[28] Y. Z. Liu, Nonlinear Vibrations, Higher Education Press, Beijing, China, 2001. 